\title{
Reconstruction of large anterior palatal fistulae using anteriorly-based dorsal tongue flaps
}

\author{
Si-Lian Fang ${ }^{1}$, Zhuo-shan Huang ${ }^{1,2}$ and Wei-liang Chen ${ }^{2 *}$ \\ ${ }^{1}$ Department of Oral and Maxillofacial Surgery, The Sixth Affiliated Hospital of Sun Yat-Sen University, Guangzhou, China \\ ${ }^{2}$ Department of Oral and Maxillofacial Surgery, Sun Yat-sen Memorial Hospital of Sun Yat-sen University, Guangzhou, China
}

\begin{abstract}
Background: We evaluate the feasibility and outcomes of the reconstruction of large anterior palatal fistulae using anteriorly-based dorsal tongue flaps or ventral tongue flaps.

Methods: Eight patients with anterior palatal fistulae using anteriorly based dorsal tongue flaps. The defect size varied from $1.0 \times 1.0 \mathrm{~cm}$ to $1.5 \times 2.0 \mathrm{~cm}$, and the tongue flap size varied from $1.5 \times 3.5 \mathrm{~cm}$ to $2.0 \times 3.5 \mathrm{~cm}$.

Results: All patients underwent successful reconstruction of palatal defects using anteriorly based tongue flaps, and no case of spontaneous detachment of the tongue flap occurred. The patients with palatal fistulae were followed up for 18-28 months, and no recurrence was encountered.
\end{abstract}

Conclusion: An anteriorly based dorsal tongue flap is a safe and feasible surgical technique for the closure of anterior palatal fistulae.

\section{Introduction}

Palatal defects generally result from congenital abnormalities. Defects such as anterior palate fistulae are usually composite tissue defects involving two types of mucosal tissue. Tongue flaps are used as regional flaps and comprise several different types, such as the deep lingual artery axial propeller flap [1], the anteriorly-based dorsal tongue flap [2], and the ventral tongue flap [3], The tongue flap is one of the main choices for the reconstruction of intraoral defects [4]. Previously, we reported on the use of double mental neurovascular island advancement flaps combined with ventral tongue flaps for the functional reconstruction of total lower lip defects [5]. Here, we evaluate the feasibility and outcomes of the reconstruction of large anterior palatal fistulae using anteriorly-based dorsal tongue flaps.

\section{Patients and methods}

Five patients with anterior palatal fistulae underwent reconstruction using anteriorly-based dorsal flaps between September 2010 and April 2016 at the Department of Oral and Maxillofacial Surgery, Hospital of Sun Yat-Sen and the Sixth Affiliated Hospital of Sun Yat-Sen University, Guangzhou, China. This study was approved by the university's Institutional Review Board. The study population included three males and two females ranging in age from 16 to 20 years (median, 19.2 years). All tongue flaps were planned to be anteriorly based. The defect size varied from $1.0 \times 1.0 \mathrm{~cm}$ to $1.5 \times 2.0 \mathrm{~cm}$ (median, $1.3 \times 1.3 \mathrm{~cm}$ ), and the tongue flap size varied from $1.3 \times 3.5 \mathrm{~cm}$ to $2.0 \times 3.5 \mathrm{~cm}$ (median, $2.0 \times$ $3.5 \mathrm{~cm}$ ). The clinical outcome was assessed by three senior maxillofacial surgeons employed at our institution. Detailed data are presented in Table 1.

\section{Case reports}

A 20-year-old man presented with a large palatal fistula measuring $1.5 \times 2 \mathrm{~cm}$ in size 10 years after repair of a bilateral cleft lip and palate (Figure 1). The patient's chief complaint concerned the regurgitation of
Table 1: Patient demographic and clinical characteristics and outcomes of the tongue flap technique for large anterior palatal fistulae.

\begin{tabular}{|l|c|c|c|c|c|c|}
\hline $\begin{array}{c}\text { Case, } \\
\text { age, sex }\end{array}$ & $\begin{array}{c}\text { Location or } \\
\text { pathology/stage }\end{array}$ & $\begin{array}{c}\text { Defect } \\
\text { size (cm) }\end{array}$ & $\begin{array}{c}\text { Tongue } \\
\text { flap (cm) }\end{array}$ & Complications & $\begin{array}{c}\text { Follow up } \\
\text { (months) }\end{array}$ & $\begin{array}{c}\text { Aesthetic } \\
\text { results }\end{array}$ \\
\hline 1, 20, M & Palatal fistula & $1.5 \times 2.0$ & $1.8 \times 3.5$ & None & 18 & $\mathrm{E}$ \\
\hline 2, 18, F & Palatal fistula & $1.5 \times 1.5$ & $2.0 \times 3.5$ & None & 18 & $\mathrm{E}$ \\
\hline 3, 19, M & Palatal fistula & $1.0 \times 1.0$ & $2.0 \times 3.5$ & None & 16 & $\mathrm{E}$ \\
\hline 4, 16, F & Palatal fistula & $1.5 \times 1.5$ & $2.0 \times 3.5$ & None & 20 & $\mathrm{~S}$ \\
\hline 5, 17, M & Palatal fistula & $1.0 \times 1.0$ & $2.0 \times 3.5$ & None & 28 & $\mathrm{~S}$ \\
\hline F: female; M: male; E: excellent appearance; S: satisfactory appearance.
\end{tabular}

fluid from the nose. His fistula was secondary to hard palate necrosis following the primary closure procedure. Because the local tissue was inadequate to close the fistula, a tongue flap was indicated. Under general anesthesia with nasotracheal intubation, the position of the patient's head was adjusted and a Kilner-Dott mouth gag was applied. An incision was made around the margins of the fistula. The mucosa of the palatal margins was then mobilized, following which the nasal lining was reconstructed by approximating the marginal flaps using 5-0 vicryl sutures (Figure 2). An anteriorly-based flap $1.8 \times 3.6 \mathrm{~cm}$ in size was designed using the tongue. The length of the flap was adjusted so that the portion of the flap from the midline was long enough to fit the anterior-posterior dimensions of the fistula with at least $1 \mathrm{~cm}$ to spare to allow the turnover section to cover and to provide some freedom for tongue movement (Figure 3). The base of the flap was adjusted so that half the width of the tongue, or, in longer fistulae, two-thirds of the

${ }^{\star}$ Correspondence to: Wei-liang Chen, Department of Oral and Maxillofacial Surgery, Sun Yat-sen Memorial Hospital, Sun Yat-sen University, 107 Yan-jiang Road, Guangzhou, China, Tel: 8620 81332429; Fax: +86 20 81332853; Email: drchen@vip.163.com

Key words: palatal fistula, tongue flap

Received: April 09, 2018; Accepted: April 24, 2018; Published: April 28, 2018 


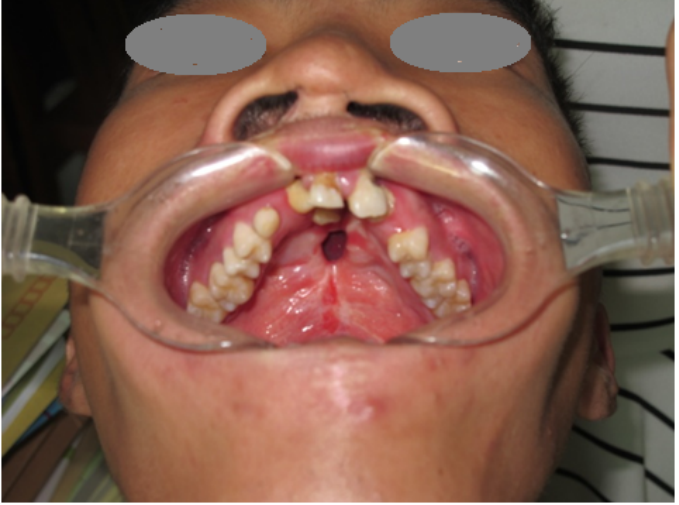

Figure 1: A 20-year-old man with a bilateral cleft lip and palate suffered from a large persistent palatal fistula

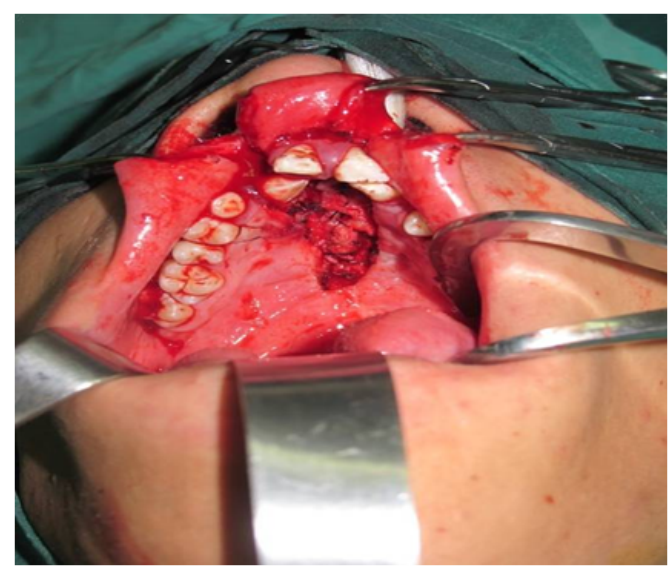

Figure 2: Nasal layer repaired by mobilization of marginal flaps from the hard palate.

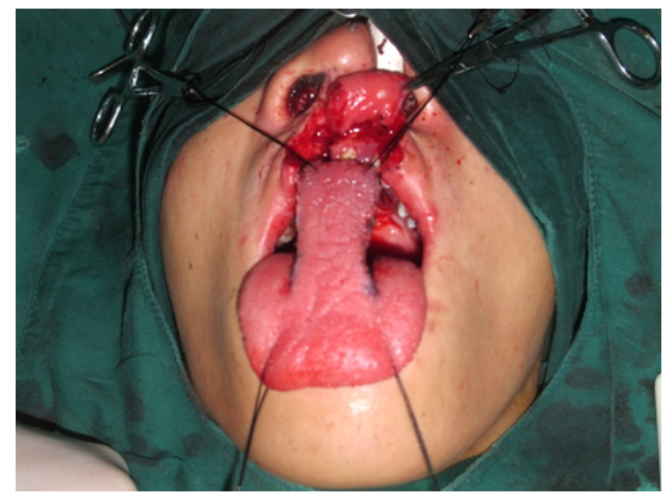

Figure 3: An anteriorly-based tongue flap was raised

width of the tongue, was involved to ensure a good blood supply to the flap. The thickness of the flap was $3 \mathrm{~mm}$ and was made to be deeper at its base to ensure a good blood supply. The tongue flap entirely covered the soft tissue defect (Figure 4). The donor site was closed directly using deep interrupted sutures. The patient was placed on an oral soft diet from the second postoperative day, followed by a semi-solid diet. After 3 weeks, the base of the flap was separated under local anesthesia, the raw surface defect was sutured, and the base of the flap remnant was returned to the tongue. Complete healing was obtained, and the patient did not show any signs of a residual fistula (Figure 5). He was followed up for 18 months, and no further regurgitation of fluid from the nose was observed. The patient showed an excellent appearance following surgery.

\section{Results}

All patients underwent surgery to achieve successful reconstruction of palatal or lower lip defects using anteriorly-based tongue flaps. No case of spontaneous detachment of the tongue flap occurred. The postoperative appearances were considered to be excellent in three patients, satisfactory in two. There were no significant effects on speech, mastication, swallowing, and shortening or narrowing of the size of the tongue. The patients with palatal fistulae were followed up for 16-28 months (median, 20 months), and no recurrence was encountered. The patients' data are presented in Table 1.

\section{Discussion}

Anterior palate fistulae are a common outcome of cleft palate surgery. These defects are usually composite tissue defects involving two types of mucosal tissue. Attempts at closing anterior palate fistulae using local tissue have resulted in a high failure rate. The anteriorlybased dorsal tongue flap was introduced by Guerrero-Santos and Altamirano in 1966 for the surgical closure of a large palatal fistula

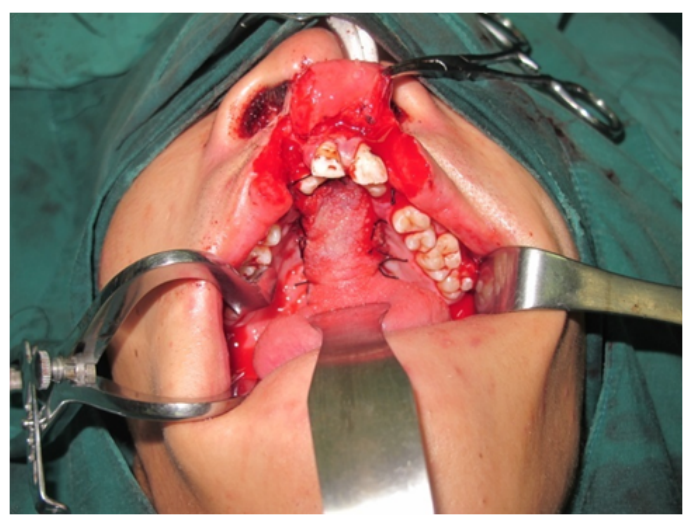

Figure 4: The tongue flap was rotated forward and sutured to the raw edges of the palatal defect anteriorly and laterally

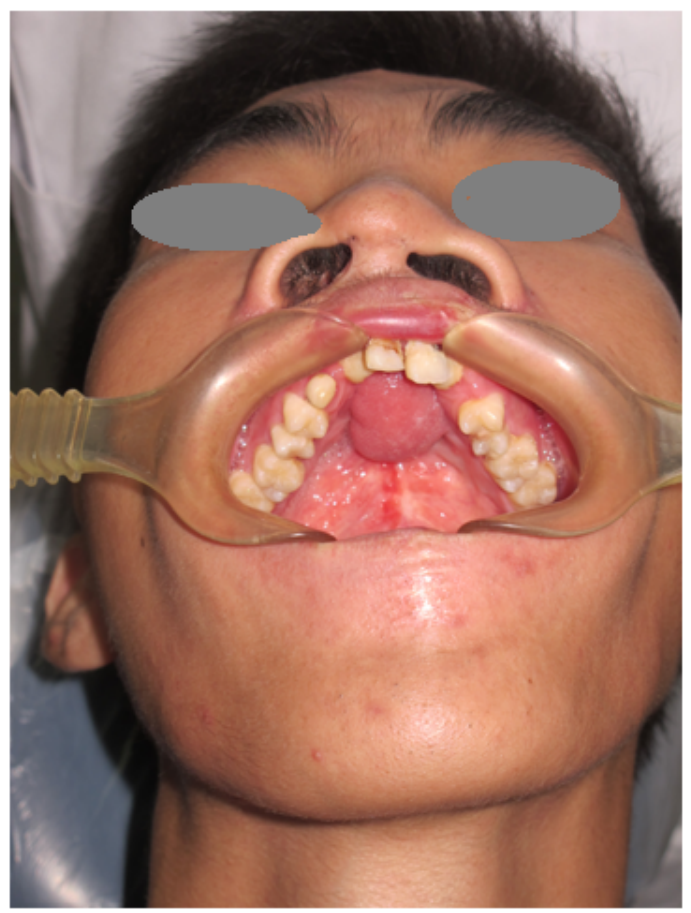

Figure 5: Intraoral view 12 months after surgery 
[2]. In that study, a 13-year-old patient with leukemia underwent the successful closure of a large palatal fistula using a tongue flap [6]. In a prospective study of 20 patients with anterior palatal fistulae (larger than $5 \mathrm{~mm}$ ), Sodhi et al. [7], reported that successful closure was achieved in $90 \%$ of cases. The anteriorly-based dorsal tongue flap is a well-accepted method for treating cleft palate patients with oronasal fistulae that cannot be closed using local tissue alone [8]. In the present study, anteriorly-based dorsal tongue flaps were used in five patients to close large palatal fistulas. All flaps survived without complications, and the postoperative appearances were considered to be either excellent or satisfactory. No recurrent fistulae were encountered in these patients. The results of this series indicate that the tongue flap is a safe technique for the closure of large, anterior palatal fistulae. The tongue has proven to be an effective source for tissue transplantation, with a rich supply of blood providing an adequate source of nutrients to the donor site. However, we believe that at least a two-layer, tension-free closure is paramount in achieving success.

No significant effect on speech, mastication, or swallowing was noted and no case of spontaneous detachment of the tongue flap occurred in our study patients. We believed that the tongue flap required the flap to be resutured to the defect using 3-0 nylon sutures that anchored the flap to the gingival and passed through and around the teeth; administration of gentle pressure was also required. The mobility of the tongue, gravitational pull, and hematoma between the tongue flap and the nasal lining play an important role in detachment [8].

It well known that the two-step procedure can act as a significant disadvantage to the utilization of this technique, in that the patient's oral function will become temporarily restricted as the mobility of the tongue is also reduced. In our case, all patients were adults aged between 16 and 20 years and were mentally healthy. They were therefore able to cope well with the treatment. Except for one case of spontaneous detachment of the tongue flap, other complications, such as postoperative bleeding [9], or venous congestion after flap division, were not encountered.

\section{Conclusion}

An anteriorly based dorsal tongue flap is a safe and feasible surgical technique for the closure of anterior palatal fistulae.

\section{Ethics approval and consent to participate}

This study was approved by the university's Institutional Review Board.

\section{Consent}

Informed written consent was obtained from each participant involved in the study.

\section{Availability of data and materials}

Data sharing is not applicable to this article as no datasets were generated or analyzed during the current study.

\section{Authors' contributions}

Si-Lian Fang helped design the study, collected patient data, analyzed the results, wrote the initial draft of the manuscript, and edited and approved the final version of the manuscript in its current form.

Zhuo-shan Huang assisted in study design, collected patient data, and edited and approved the final version of the manuscript in its current form.

Wei-liang Chen conceived the study, oversaw the design of the study, oversaw all clinical and technical aspects of the study, helped analyze the data, provided guidance in the initial draft of the manuscript, and edited and approved the final version of the manuscript in its current form.

\section{References}

1. Cordova A, Toia F, D'Arpa S, Giunta G, Moschella F (2015) A new mucosal propeller flap (deep lingual artery axial propeller): the renaissance of lingual flaps. Plast Reconstr Surg 135: 584e-594e. [Crossref]

2. Guerrero-Santos J, Altamirano JT (1966) The use of lingual flaps in repair of fistulas of the hard palate. Plast Reconstr Surg 38: 123-128. [Crossref]

3. Kheradmand AA, Garajei A (2013) Ventral tongue myomucosal flap: a suitable choice for shaved lower vermilion border reconstruction. J Craniofac Surg 24: e114-e116. [Crossref]

4. Ceran C, Demirseren ME, Sarici M, Durgun M, Tekin F (2013) Tongue flap as a reconstructive option in intraoral defects. J Craniofac Surg 24: 972-974. [Crossref]

5. Chen WL, Wang YY, Zhou M, Yang ZH, Zhang DM (2012) Double mental neurovascular $\mathrm{v}-\mathrm{y}$ island advancement flaps combined with tongue flaps for functionally reconstructing total lower-lip defects. J Craniofac Surg 23: 181-183. [Crossref]

6. Herford AS, Tandon R, Pivetti L, Cicciù M (2013) Closure of large palatal defect using a tongue flap. J Craniofac Surg 24: 875-897. [Crossref]

7. Sodhi SP, Kapoor P, Kapoor D (2014) Closure of Anterior Palatal Fistula by Tongue Flap: A Prospective Study. J Maxillofac Oral Surg 13: 546-549. [Crossref]

8. Agrawal K, Panda KN (2007) Management of a detached tongue flap. Plast Reconstr Surg 120: 151-156. [Crossref]

9. Guzel MZ, Altintas F (2000) Repair of large, anterior palatal fistulas using thin tongue flaps: long-term follow-up of 10 patients. Ann Plast Surg 45: 109-114. [Crossref]

Copyright: (C2018 Fang SL. This is an open-access article distributed under the terms of the Creative Commons Attribution License, which permits unrestricted use, distribution, and reproduction in any medium, provided the original author and source are credited. 